BULLETIN Bulletin hispanique

HISPANIQUE Université Michel de Montaigne Bordeaux

120-1 | 2018

Varia

\title{
Los gentilicios en el Diccionario de Autoridades
}

Les gentilés dans le Dictionnaire des Autorités

Gentilés in the 'Diccionario de Autoridades'

\section{Dolores Garcia Padrón}

\section{OpenEdition}

\section{Journals}

Edición electrónica

URL: https://journals.openedition.org/bulletinhispanique/5352

DOI: 10.4000/bulletinhispanique.5352

ISSN: 1775-3821

\section{Editor}

Presses universitaires de Bordeaux

\section{Edición impresa}

Fecha de publicación: 30 junio 2018

Paginación: 69-86

ISBN: 979-10-300-0298-0

ISSN: 0007-4640

Referencia electrónica

Dolores Garcia Padrón, «Los gentilicios en el Diccionario de Autoridades», Bulletin hispanique [En línea], 120-1 | 2018, Publicado el 01 enero 2022, consultado el 08 enero 2022. URL: http:// journals.openedition.org/bulletinhispanique/5352 ; DOI: https://doi.org/10.4000/bulletinhispanique. 5352 


\title{
Los gentilicios en el Diccionario de Autoridades ${ }^{1}$
}

\author{
Dolores García Padrón \\ Universidad de La Laguna - Tenerife
}

Le Diccionario de Autoridades recueille une centaine de gentilés au nombre desquels les gentilés définis comme dérivés d'un nom de lieu sont minoritaires, la priorité étant donnée à l'enregistrement des termes lexicalisés au XVIII e siècle. Ce travail analyse la notion de gentilé d'un point de vue sémantique ainsi que divers aspects de la définition lexicographique des gentilés.

Mots-clés: Gentilé, nom de lieu, définition lexicographique, Diccionario de Autoridades.

El Diccionario de Autoridades recoge unas cien voces gentilicias, entre las que son minoría las definidas como derivados de nombre de lugar, pues se prioriza el registro de las lexicalizaciones de estas voces en el siglo XVIII. En este trabajo se reflexiona desde un punto de vista semántico sobre la noción de gentilicio y se analizan varios aspectos de su definición lexicográfica.

Palabras clave: Gentilicio, nombre de lugar, definición lexicográfica, Diccionario de Autoridades

The Diccionario de Autoridades collects about a hundred gentilés, among which the gentilés defined as derived from a place name are a minority. Priority is given to the registration of terms lexicalized in the $18^{\text {th }}$ century. The present work will analyse the notion of gentilé, from a semantic point of view, as well as diverse aspects of the lexicographical definition of gentiles.

Keywords: Gentilic, place name, lexicographical definition, Diccionario de Autoridades.

1. Este trabajo se enmarca en el Proyecto de Investigación Estudio global de los gentilicios de la lengua española: materiales americanos, nuevas consideraciones y gestión informática de los datos (Ministerio de Economía y Competitividad español, FFI2011-26256). 


\section{El adjetivo gentilicio}

El adjetivo de relación que llamamos gentilicio posee una expresión variada en las distintas lenguas. De un modo general podríamos decir que, en español, estas palabras con las que designamos a las personas, los animales y las cosas relacionadas con un determinado lugar tienen su expresión prototípica en un adjetivo que se forma a partir de un topónimo mediante los procedimientos morfológicos habituales en esta lengua. Presentadas así las cosas, se podría pensar que los gentilicios españoles constituyen una mera nómina de voces deducibles de los nombres geográficos y que este catálogo es un conjunto de etiquetas asépticas que remiten directamente e invariablemente a un grupo humano y a todo lo relacionado con él. No vamos a detenernos en una caracterización exhaustiva de los gentilicios como etnónimos o epónimos, pero se hace necesario puntualizar algunos aspectos de estas unidades para poder entender el sentido que tiene estudiar cómo el primer diccionario académico español se enfrentó en el siglo XVIII a su recogida y definición.

En primer lugar, no todos los gentilicios hispánicos son detoponímicos; la necesidad de nombrar a los demás como grupo ha hecho que los hablantes recurramos, además de a los nombres geográficos ${ }^{2}$, a otra clase de nombres propios como los antroponímicos, según vemos en panchito $^{3}$ (< México); a nombres comunes de lugar, como serrano (<Alameda del Valle, Madrid, España) o llanero (< Parla, Madrid, España); a nombres comunes de valor denotativo no espacial, como ladrón (<Alcolea de Tajo, Toledo, España ) o macho (<Aldeanueva de Barbarroya, Toledo, Espańa); a adjetivos como ranero (<Adalla, Valladolid, España) o lagartero (<Alajeró, isla de La Gomera, España); o a expresiones sintagmáticas tales como del pilorro (< La Alberca de Zánzara, Cuenca, España), de la navaja (<Albacete, España) o de los labios envueltos $(<\text { Alcoroches, Guadalajara, España })^{4}$, para identificar a los naturales de un territorio (De la Torre Aparicio 2006, s.v.). Todas estas voces y expresiones deben ser consideradas, a nuestro juicio, miembros de pleno derecho de la clase de las palabras gentílicas, pues cumplen del mismo modo la función semántica básica de estas unidades, que podríamos definir como la 'vinculación a un territorio'; y aunque parezca que palabras como bagañete-vagañete, catracho, gringo, pucelano o tico, que -en principio- significan la mencionada relación con los territorios de Tazacorte (isla de La Palma, Canarias), Honduras, EE UU

2. Habría que distinguir entre los gentilicios que tienen en su base un nombre de naturaleza antroponímica, un nombre común, etc., que funciona como topónimo, como dombenitense (<Don Benito, Badajoz, España), del que por tanto el gentilicio que se deriva es un detoponímico, del gentilicio que está formado directamente del nombre antroponímico, del nombre común, etc., que es al que nos referimos en estos casos.

3. En adelante se obviará la forma femenina de las palabras gentilicias, salvo en los casos en que sea necesario hacerla constar.

4. Estos últimos habría que distinguirlos de los gentilicios sintácticos propiamente dichos del tipo de Carabanchel > de Carabanchel. 
de América, Valladolid (Espańa) y Costa Rica, respectivamente, son miembros de segundo orden de esta clase, pues con frecuencia implican valoración negativa, lo cierto es que estos que frecuentemente llamamos gentilicios léxicos o seudogentilicios ofrecen al hablante un espacio en el que proyectar un sinfín de valores identitarios que están sustentados en sus funciones semántica y pragmática. Los gentilicios propiamente dichos y los seudogentilicios son, obviamente, mecanismos expresivos de distinta naturaleza y trascendencia lingüístico-social (Herrera Santana 2012a y 2012b), y, como se verá, ambos disfrutan de una larga tradición de uso en español (Cela 1998, Cruz Herrera 1997, García Gallarín 2003, Sánchez Salas 2009, Morera 2012a).

Con respecto a los gentilicios detoponímicos, o propiamente dichos, hay que señalar que en su formación se observan dos procedimientos diferentes. El más general y frecuente hoy en día es el que consiste en la adición de un sufijo (-ense, -és, -ero, -eño, -ano, -ino, etc.) a una base toponímica; esta derivación morfológica sigue unos patrones más o menos regulares en español (Garcés Gómez 1988, García Gallarín 2003, García Padrón 2012), de modo que lo que ocurre es la transformación de un nombre propio de lugar en un adjetivo de relación, valor sustentado en alguno de los morfemas sufijales que suelen estar «habilitados» para esa función denotativa (Almela 2013; Herrera Santana 2016a; Pérez Vigaray y Herrera Santana (en prensa)): Francia > francés, Panamá > panameño... El otro modelo de formación es mucho menos frecuente hoy en día y consiste en la mera adjetivación del nombre propio, de manera que, aun no recibiendo la base toponímica incremento morfológico alguno, se opera un cambio categorial por el cual el margen de la palabra pasa a reinterpretarse en clave morfológica: Bohemia > bohemio, mia o Arabia > arabio, bia. Obsérvese la diferencia entre bohemiano o arábigo, derivados morfológicos, y bohemio o arabio, adjetivaciones de los mencionados topónimos. En estos dos últimos casos hablaríamos de derivación semántica: del sustantivo identificativo de lugar al adjetivo de relación con el lugar5.

\section{LA DEFINICIÓN LEXICOGRÁFICA DEL GENTILICIO}

El tratamiento que han recibido estas unidades léxicas en la lexicográfica hispánica desde el Tesoro de Covarrubias y Autoridades hasta la actualidad ha sido desigual: algunos diccionarios simplemente no las recogen, otros se limitan a listarlas en un anexo junto al topónimo formal correspondiente y muchos las incluyen en el cuerpo del diccionario. En el caso de estos últimos, a pesar de la relativa heterogeneidad de su descripción, se observa una constante: la definición del valor básico de estos adjetivos es siempre la referencia a

5. Sobre el proceso de derivación de topónimos a partir de gentilicios, como en ruso $>$ Rusia, italo $>$ Italia, alemán > Alemania, etc., véanse el señero trabajo de Benveniste (1979), la Gramática de la RAE (2009) o el más reciente de Morera (2012, especialmente págs. 126 y ss.), que apoyan la idea de la no existencia de derivación regresiva en estos casos. 
la persona y secundariamente la relación de los animales, las cosas, etc., vinculados a ella. En la lexicografía española de las últimas décadas, salvando unas pocas excepciones (como la del Diccionario CLAVE, que los define así: español: "De España o relacionado con este país europeo»), esto se concreta en dos acepciones: 1. 'natural de' y 2. 'perteneciente o relativo a'. Y siendo esto, efectivamente, representativo del funcionamiento de estas unidades, pues no cabe duda de la primacía del individuo y del grupo al que pertenece por su vinculación con un territorio, respecto de los animales o las cosas, parece más adecuado desde el punto de vista semántico, como veremos seguidamente, usar la definición de la segunda acepción como valor general de la función, que podríamos formular como 'vinculación a un territorio', respecto de la cual la primera subacepción sería la relativa a persona, la segunda sería la relativa a animales, la tercera la relativa a cosas, etc. (García Padrón y Morera 2015).

Es evidente que esta primera subacepción es la que hace del gentilicio una clase de palabras particular en las lenguas, pues es el sentido a partir del cual se desarrollan mayoritariamente otros valores denotativos secundarios, terciarios, etc. Las características físicas, psicológicas o morales de la gente, la lengua de que se sirve para hablar, los objetos de todo tipo que usa, en definitiva, cualquier aspecto concerniente a los grupos humanos va integrándose en estas voces en forma de rasgo sémico, lo cual va especificando de un modo cada vez más preciso el valor de relación originario. Así, la significación gentilicia no solo genera sentidos adjetivos (calificativos o identificativos) y sustantivos específicos -como 'tartamudo' (El Salvador) o 'tonto' (Costa Rica) para gallego (DRAE- $\left.01^{6}\right)$; 'rudo, bruto, inculto' para abisinio (Sierra de Segura, Jaén, España) (Alvar Ezquerra 2000, s.v.); 'lengua hablada en Cataluña' para catalán (DRAE-14); 'cigarro puro' para habano (DRAE-14, s.v.), etc.-, sino que a veces estos empleos dan lugar a lexicalizaciones diversas en las que la relación con el gentilicio va haciéndose cada vez más remota; como muestra, llamamos campechano al que es 'cordial' (< Campeche, ciudad y estado de México), se usa moro es el sentido peyorativo de 'celoso' (< Mauritania), los entendidos en fútbol comentan jugadas como la chilena (<Chile) o aderezamos los platos con salsas como la bearnesa ... Los estadios más evolucionados de este proceso se pueden observar, por ejemplo, en voces como esclavo o galgo, lexicalizaciones antiguas de los gentilicios eslavo y gálico, cuyos significantes, una vez fijados los nuevos valores semánticos y libres por tanto de la servidumbre semántica gentilicia, han evolucionado hasta llegar a las formas actuales, palabras que el hablante de esta sincronía no relaciona ya con el derivado gentilicio originario.

Como se ve, los gentilicios son voces receptáculos de todos aquellos variados elementos que su uso lingüístico-pragmático comporta, y que termina por absorberlos y sistematizarlos como parte de su función denotativa. En muchos casos, no son palabras inocentes y en esas ocasiones no solo aportan

6. En las enmiendas a la vigésima segunda edición que están disponibles en la web de la RAE como Avance de la vigésima tercera edición, ya no figura la acepción de 'tonto' y en la nueva edición de 2014 ha desaparecido también la de 'tartamudo'. 
información del otro al que se designa con dicha voz, sino de nosotros mismos, pues al nombrar creamos una identidad generalmente negativa que revaloriza (consciente o inconscientemente) la nuestra propia (García Padrón 2015).

Por todo ello, creemos que los diccionarios deben recoger los gentilicios (evidentemente, siempre con la caracterización debida en función del tipo de obra lexicográfica de que se trate) y definirlos, en los casos en que sea necesario, yendo más allá de las consabidas denotaciones de 'natural de' y 'perteneciente o relativo a' a las que hemos aludido, pues solo de ese modo, es decir, dando cuenta de la compleja y amplia variación que desarrollan como verdaderas palabras de un idioma, pueden ser descritas adecuadamente (Morera y García Padrón 2015). Y por lo que respecta a aquellos casos en que el proceso de lexicalización ha conducido a la desaparición de la función gentilicia originaria y a la consolidación de un nuevo valor denotativo, parece razonable darles a esos adjetivos y sustantivos una entrada independiente en la que se precise su significación y se especifiquen todas aquellas acepciones a que hubiera dado lugar; pensemos, por ejemplo, en todas las acepciones que esclavo posee hoy en día en español (DRAE-2014, s.v.).

\section{Los gentilicios en el DiCCIONARIO DE AUTORIDADES}

En esta obra inaugural, nuestros primeros académicos se enfrentaron explícita e implícitamente a los problemas clave de estas voces especiales. En primer lugar, es necesario señalar que el Diccionario de Autoridades (en adelante DA), a diferencia del Tesoro de Covarrubias (Morera 2015), que lo antecede en poco más de un siglo, recoge una nómina escasa de denominaciones gentilicias; en total son solo algo más de cien voces, algunas de las cuales presentan varias subentradas $^{7}$ en las que se da cuenta de sus diversos sentidos, lo cual hace aumentar el número de entradas en al menos un $25 \%$. De estos, solo unos cuarenta son gentilicios con función gentilicia, esto es, gentilicios propiamente dichos de los que se consigna su valor de relación con un lugar, del tipo AFRICANO, ARABE, BURGES, DAMASQUINO, GALLEGO, INDIO, MONTAÑES ${ }^{8}$, etc. El resto de entradas son lemas gentilicios bajo los que se da cuenta del resultado de la lexicalización de acepciones secundarias, terciarias, cuaternarias, etc., del valor de relación original; es decir, la mayoría de las entradas gentilicias son del tipo albanes 'el que juega a los dados', alicantina 'treta', BoEmio 'tipo de capa', FLAMENCO 'ave acuática', FRISON 'tipo de caballo' o 'grande, corpulento', GERMANO 'puro', POLACA 'vuelta del zapato', ROMANA 'balanza', ZARAGOCI 'especie de ciruela', etc. El estudio de estas fijaciones léxicas no puede hacerse

7. Desde la primera edición hasta la sexta de 1822 , cada significado se recoge en entrada independiente y a partir de la séptima de 1832 ya aparecen agrupadas. Véase Alvar Ezquerra (1983, págs. 217 y ss.).

8. En adelante, se respetará la ortografía del original: el lema gentilicio en mayúsculas y sin tilde y en minúscula con tilde en el cuerpo de la definición. Se obviarán también, en los casos en que el DA las proporciona, las formas femeninas del gentilicio. 
sin tener en cuenta previamente qué unidades gentilicias propiamente dichas se anotan en este repertorio, de qué manera se define su valor de pertenencia en los dos niveles seńalados, personal y no personal, y qué otros elementos definitorios aparecen en sus artículos lexicográficos correspondientes, aspectos que abordaremos a continuación.

Este estudio se ha hecho sobre la primera edición del $\mathrm{DA}^{9}$, profusa y primorosamente analizada y a la que académicos como Fernando Lázaro Carreter (1972) o José Manuel Blecua (2006) dedicaron sus discursos de ingreso a la institución española. Se sabe sobradamente (Gili Gaya 1963, Casares 1969, Lázaro Carreter 1972, Alvar Ezquerra 1983 o Hernando Cuadrado 1997, entre otros) que el DA fijó su planta, y así se indica en el Prologo, a partir de varios diccionarios europeos y con adiciones y supresiones constantes (Lázaro Carreter 1972, Álvarez de Miranda 1995, Freixas 2004), pero sobre todo, como expresamente se señala, tuvo en la obra de Covarrubias su modelo:

Pero la Real Académia, venerando el noble pensamiento de Covarrubias, y siguiendole en las voces en que halló proporción y verisimilitud ${ }^{10}$, ha formado el Diccionario, sujetandose à aquellos princípios, y continuando despues debaxo de las reglas que la han parecido mas adequadas y convenientes, sin detenerse con demasiada reflexión en el orígen y derivación de las voces: porque [i.II] además de ser trabajo de poco fruto, sería penoso y desagradable à los Lectores, que regularmente buscan la propriedád del significado: y el orígen ò la derivación, quando no es mui evidente y claro, quedaba siempre sujeto à vários conceptos, despues de ser desapacible su lección, y que ocasionaría un volumen fastidioso y dilatado. (Prologo, I y II)

Resulta sorprendente que casi cuadruplicando el DA el número de voces del Tesoro (39000 $00{ }^{11}$ frente a 11000 , aproximadamente), la nómina de gentilicios que recoge el repertorio académico sea sin embargo mucho menor. Pero ello también recibe su explicación en este Prologo, en el que se declara explícitamente que no se incluyen nombres de lugar ${ }^{12}$ :

[...] y han quedado excluidas del Diccionario todas las voces y nombres próprios de personas y lugáres, que pertenecen à la História, y à la Geographia [...] (Prologo,VI)

Por tanto, teniendo en cuenta, en primer lugar, que el Tesoro recoge topónimos, cosa que no hace el DA, y que, exceptuando las lexicalizaciones, buena parte de los gentilicios que anota se definen en el propio artículo del topónimo de base; considerando, en segundo lugar, que el DA no incluye

9. Es decir, no se ha tenido en cuenta la segunda edición que se hizo en 1770, reedición del tomo I (letras A y B) de la primera edición, en el que hay supresiones y adiciones de más de 700 y 2200 términos, respectivamente (véase Garrido Moraga 1987 y 1992), y cuyo estudio podría arrojar alguna luz para ver la transición, en lo que a los gentilicios se refiere, entre el DA y la siguiente edición del diccionario académico de 1780, ya en un solo tomo y sin autoridades.

10. La negrita es nuestra.

11. Según Lázaro Carreter $(1972,75)$, «[...] más de treinta y siete mil seiscientas entradas, y muchos millares más de acepciones, modismos y refranes.»

12. La negrita es nuestra. 
nombres propios de lugar (por lo tanto no se aprovecha el material gentilicio de Covarrubias); y sabiendo, en tercer lugar, que fue su objetivo no detenerse en el origen y en la derivación de las voces, no resulta sorprendente que la escasez de gentilicios anotados sea la nota predominante en esta primera aventura lexicográfica. Para justificar el hecho de que haya un mayor número de entradas de lexicalizaciones que de gentilicios con función gentilicia, quizá habría que volver sobre el Prologo y leer en clave semántica el deseo de los académicos de atender a los lectores, que buscan la «propriedad del significado», es decir, deseaban brindarle al lector la posibilidad de conocer los significados «nuevos», los que se iban lexicalizando e independizando de su valor originario, pues su idea era que los otros podría derivarlos directamente de sus topónimos correspondientes. Y esta acertada decisión, consciente o inconsciente, sorprende en un diccionario hecho por gente, en palabras de Lázaro Carreter, "carente de preparación lexicográfica» (1972: 88) y sin idea aproximada de cuál debía ser la planta, que fue realmente definiéndose a medida que avanzaba la obra (entre otros, Freixas 2006).

\section{Los gentilicios con función gentilicia del DA}

Tal como hemos señalado, hay aproximadamente unos cuarenta gentilicios de tipo muy variado que pueden ser clasificados atendiendo a puntos de vista de distinto orden, pero con un denominador común: el valor de 'vinculación a un espacio' que anota el DA para ellos concierne bien al uso personal bien al uso no personal o a ambos; $y$, en algunos casos, también se incluyen bajo la misma entrada, como se verá, algunos datos sobre las fijaciones a que han dado lugar.

A) Si atendemos a la naturaleza del sustantivo que les sirve de base, hay una decena de derivados de nombre común de lugar, como son ALDEANO, BURGES (villa o ciudad), CIUDADANO y CIBDADANO (bajo entradas independientes), ISLEÑO, MONTAÑES, SERRANO, URBANO, NACIONAL O VILLANO, y otro conjunto más amplio de derivados toponímicos ${ }^{13}$. Es resaltable que en la definición de estos gentilicios, el nombre común del que derivan o al que se refieren figure siempre en mayúscula, como si de un nombre propio toponímico se tratara: Aldea, Isla, Montaña...

B) Entre los detoponímicos, encontramos igualmente un grupo heterogéneo de treinta unidades que son gentilicios relativos a continentes, como AFRICANO, ASIATICO y EUROPEO; a países, como ARABE, ESPAÑOL, HISPANO, IBERO, INDIO, MARROQUI, MORO y TURCO; a ciudades, como BURGUENTO (< Burgos), DAMASQUINO o ROMANO; y finalmente a regiones, como Castellano, gallego, levantino y levantisco (en entradas

13. Entre los derivados de nombre común también se recoge algún adjetivo derivado de gentilicio, como ALDEANIEgo, definido como "Cosa que pertenéce à la Aldéa, ò que tiene sus resábios.» 
independientes) o LATINo. Entre ellos, cabría incluir ARABICO $\sim$ ARABIGO (anotados bajo la misma entrada), que pueden interpretarse también como derivados morfológicos gentilicios.

Casos distintos son los de Hebreo o judio; del primero se da una definición gentilicia en relación con el pueblo bíblico ${ }^{14}$ ("Además del sentido recto del que es de la Nacion hebrea, ò cosa perteneciente à ella [...]») y del segundo, siendo un derivado morfológico toponímico, bajo la entrada propiamente gentilicia, se da una definición secundaria ("Cosa perteneciente à Judíos.»).

Hay también, entre los detoponímicos, derivados morfológicos de los que se indica solo la función gentilicia no personal. Son los casos de ALEMANISCO, BARBARESCO, JUDAICO, MORISCO o MORISCOS ${ }^{15}$. Valga como ejemplo la definición de BARBARESCO: «Cosa própia y perteneciente à los bárbaros: como trage barbaresco, forma barbaresca.»

Otro pequeño grupo lo constituyen aquellos que pueden ser considerados derivados de topónimos o de gentilicios pero que se aplican a grupos humanos diferentes (Morera 2012b). Son los casos de boemiano (< Boemia / < boemio) o EgIPCIANo (< Egipto / < egipcio), que se definen como aplicados a 'gitano'.

C) Por último, encontramos también anotados gentilicios léxicos o seudogentilicios como GABACHO, GITANO o CORITO, que aluden, respectivamente, a los franceses, a los que afectan «ser de Egypto» o a la denominación que anotan como antigua para montañeses y vizcaínos.

Como se puede observar, la selección de las voces no parece responder a ningún criterio, más allá probablemente de las decisiones individuales de cada redactor ${ }^{16}$. Lo más que se puede decir es que las voces que se incluyen están obviamente relacionadas de alguna manera con nuestra historia y cultura y la de los pueblos que en ellas habían tenido un papel relevante desde la perspectiva de los académicos del siglo XVIII ${ }^{17}$.

\section{La definición de la función gentilicia en el DA}

La característica predominante de esta obra es la disparidad de criterios que se manifiesta en todos los aspectos. Como dice Lázaro Carreter, hay «falta de método" y todo se hace «conforme al genio de los autores» $(1972,85)$. Hay,

14. El gentilicio hebreo ( < latín hebraeus < hebreo 'ibrī < probablemente del acadio hapiru[m], 'paria') ilustra bien cómo un nombre común deviene en nombre colectivo referido al conjunto de individuos que profesa una religión, y termina especializándose en un etnónimo.

15. Hay dos entradas, una para MORISCO y otra para MORIsCOS.

16. Véase el interesante artículo ya citado de Freixas (2006) a propósito del trabajo encomendado al académico Ferreras, sus anotaciones y la eliminación de, por ejemplo, la voz gentilicia ASTURIANOs. Véase también Lázaro Carreter (1972), que insiste a cada paso en los cambios de rumbo y la falta de método que caraterizó la elaboración de esta obra.

17. Acerca de la ideología que revelan las definiciones académicas, véase Hernando Cuadrado (1997, págs. 399), entre otros. 
pues, poca regularidad en la manera de presentar la información en las entradas y subentradas, en la longitud y desarrollo de los artículos, en la información sobre la categoría o la etimología, en las autoridades que ilustran los sentidos, $y$, claro, tampoco la hay en la definición propiamente dicha.

Por lo que se refiere a las entradas, se señala que ${ }^{18}$

La priméra vez que se ponen las voces para explicarlas se han escrito con letras versáles, para que se puedan hallar con mayor facilidád, y quando se repiten en artículo aparte, por razón de tener otro sentído, ò estar en princípio de phrase, ò refrán, se ponen con versalillas. [Prologo, VI]

Probablemente por esa razón las lexicalizaciones de los gentilicios suelen disponer de entradas independientes. Por ejemplo, para FRISON hay una entrada relativa a las cualidades de los caballos con una subentrada en la que se da cuenta de los usos más generales de 'fuerte, corpulento', ninguna de ellas gentilicia; pero bajo ALEMANISCo tenemos en una única entrada la acepción adjetiva no personal gentilicia junto a la lexicalización sustantiva:

Cosa perteneciente à Alemánia, de cuyo nombre está formada esta palabra: la qual en el uso de nuestra léngua se aprópria à cierto género de mantelería fabricada y texída à quadraditos, algo mayores que la que se llama de gusanillo: y porque este texido vino la priméra vez de Alemánia, se le dió el epitheto de Alemanisco.

En general, se observa que la entrada principal es la que da cuenta del valor gentilicio personal, del no personal o de ambos conjuntamente y solo en unos pocos casos se individualizan en subentradas los otros sentidos, como podemos ver bajo GALLEGo, cuya primera entrada se refiere a la acepción adjetiva no personal, y la subentrada a la sustantiva 'viento cauro'; o ROMANO, que tiene en la entrada principal la acepción no personal y como subentradas los sentidos sustantivos fijados de «[...] gato manchado à listas de pardo y negro» y «[...] melocotónes mui grandes y gustosos [...]». Lo mismo en INDIANO: la primera entrada para la acepción no personal y las dos subentradas para los sentidos sustantivos relativos a "[...] el sugéto que ha estádo en las Indias, y despues vuelve à España [...]» y "[...] el mui rico y poderoso.» Y, desde luego, llama la atención el hecho de que un gentilicio español tan importante desde el punto de vista histórico-social como CASTELlano reciba su definición gentilicia como subentrada tercera y penúltima (abre el artículo la acepción «Alcáide o Gobernadór que manda algun castíllo [...]» y lo cierra la expresión adverbial en castellano $^{19}$ ). Caso aparte es el de Turco, que dispone de dos entradas, una para la acepción personal, otra para la no personal y, como subentrada de esta, la lexicalizada referida al 'vino', marcada como de germanía. Pero, por ejemplo, en ISLEÑO tenemos en la entrada principal la acepción personal y en la subentrada la no personal. Como se ve, la irregularidad es lo predominante.

18. La negrita es nuestra.

19. En puridad, habría que separar en entradas diferentes el adjetivo CASTELLANo derivado de castillo y el adjetivo gentilicio castellano, que es un derivado del topónimo Castilla. 
En lo que concierne a la definición gentilicia, hay que señalar que el DA, a diferencia del Tesoro, define la mayoría de los gentilicios que recoge en su acepción no personal. Son escasamente una decena los que refieren la relación del individuo, de la persona con el topónimo o el nombre común de lugar con el que están vinculados. Son los casos de ALDEANO, BURGES, ESPAÑol, GABACHO, gitano, hebreo, indio, isleño, Latino, morisco, moro o serrano. Su definición, siempre en torno a la idea de 'lo natural de', no sigue tampoco un patrón constante, siendo los siguientes esquemas los más habituales:

a) «El naturál de...» (isleño1, gabacho o moro), «El naturál de y nacido en...» (español), «El vecíno ò naturál de...» (BURGES, CIUDADANo), «El que era natural o gozaba de los privilegios...» (latino) o «El natural de..., originario de aquellos Reinos, hijo de...» (indio);

b) "Persona que es de...» (ALDEANO), «El que habita en... ò ha nacido en...» (SERRANo), "Cierta classe de gentes...» (Gitano), "De la nación...» (hebreo) o «Se llamaban aquellas gentes de ...» (MORIscos). También se echa mano de definiciones sinonímicas en casos como los de BOEMIANo «El (gitano)» o las de EGIPCIANO o Hispano, de los que se dice «Lo mismo que (gitano, español) ...”

Como era de esperar, según las consideraciones que hemos hecho al comienzo, la mayoría de los gentilicios se describen en sus acepciones no personales y en este primer diccionario académico se definen, como en el Tesoro, en relación con la idea de 'pertenencia' bien al topónimo bien al gentilicio correspondiente; por ejemplo, INDIANO es "Cosa perteneciente a Indias", pero JUdio es "Cosa perteneciente a los judíos», y a veces a los dos: ROMANo es "Lo que pertenece à Roma, ò à los Romanos». Las variantes de esta acepción son las siguientes:

a) «Lo que pertenéce à...» (MORISCO o ROMANO), «Lo que toca pertenece à...» (ISLEÑo2, LeVANTISCO / LEVANTINO), "Lo que es própio de...» (MARROQUi), "Lo que es própio de ò pertenéce à...» (CASTEllano), «Lo que pertenéce à ò es própio de...» (URbano), «Lo perteneciente a...» (DAMASQUINO, EUROPEO, IBERO);

b) "Cosa de...» (ALDEANo, ARABE), "Cosa perteneciente à... ò su territorio» (BURgueÑo), "Cosa perteneciente à ...» (GALlego, INDIANO, AFRICANO, ALEMANISCO, ARABICO ARABIGO) o «La COSa que pertenéce ò es del...» (ASIATICO).

En algunos casos, hay incluso mezcla de ambas: NACiOnal es «Lo que es proprio de... ò es natural de...» y MONTAŃES es «Lo que toca o pertenece à..., es nacido ò trae su origen de ellas.», definiciones en las que, en contra de lo esperado, la acepción personal va en segundo lugar. Otras veces la definición es una paráfrasis (Alvar Ezquerra 1983,216) en la que se mezclan los sentidos personales, los no personales, las especificidades semánticas, las connotaciones, algunas marcas de uso, etc. Veamos lo que dice el DA del seudogentilicio CORITO: 
CORITO. s. m. Nombre que se daba antiguamente à los Montañéses y Vizcainos. Son varias las opiniones sobre el origen de esta palabra. Covarr. siente que viene del nombre Griego Corytus, que significa Aljaba ò carcax, porque llevaban un haz de dardos ò lanzuelas arrojadizas dentro de ella. Otros pretenden sea nombre proprio del Dardo, que en Griego se dice Corythaix, que vale impetuoso, ò violento; pero lo más verisimil es que viene de la voz Latina Corium, que significa Cuero, porque usaban de ellos, y se cubrian para su defensa. Oy se les dá este nombre à los Asturianos por zumba y chanza. Lat. Astur, is. PANT. Rom. 3.

Pulga joven, pulga adulta,
bodegonéa el sobáco
del corito palanquin
del Montañés Asturiano.

Como se observa, no es posible deducir del análisis de estos modos de definir conclusión alguna más allá de que es más frecuente encontrar la acepción personal o una combinación de la no personal más la personal en los gentilicios derivados de nombres comunes. Estas definiciones habría que ponerlas en relación con las citas de autoridades que se proporcionan ${ }^{20}$. En general, los ejemplos que ilustran las acepciones personales suelen estar en consonancia con ellas. En el caso de las no personales, hay menos regularidad, COmo en ALDEANO, ESPAŃOL o NACIONAL; y lo que es una constante en ambas es la abundancia de citas o simples ejemplos de la acepción terciaria relativa a la 'lengua hablada por...'.

Otro aspecto del artículo lexicográfico que merece la pena ser destacado es el de las etimologías que acompañan la definición. En la de los gentilicios con función gentilicia suelen ser etimologías propiamente dichas, es decir, generalmente son gentilicios latinos como africanus, arabicus, castellanus, europeus, gallaicus, a, um, insulanus, marocanus, etc., lo cual se hace explícito en algunos casos, como en Asiatico: «Es voz puramente latina. Asiaticus.» ${ }^{21}$, pero también las hay francesas, como boemien para BOEMIANo о bourgeois para burges, del que se aporta también la etimología latina equivalente: civis, is. Pero la información etimológica que proporciona el DA en el caso de las lexicalizaciones gentilicias son equivalencias semánticas latinas del sentido en que se ha fijado esa unidad. Por ello, en un caso como el de ALEMAnisco, del que se anotan una acepción no personal y una lexicalización, la de 'cierto tipo de mantel', la etimología es su equivalente semántico en lengua latina, que en este caso es un sintagma: mappae alemaniccae.

Los seudogentilicios constituyen en este sentido un caso aparte, pues, como se señaló más arriba, los datos sobre su origen van ligados, en su definición parafrástica, a la motivación del nombre, la indicación de marcas de uso, etc. Veamos como ejemplo la definición de GABACHO $^{22}$ :

20. No se aportan para ALDEANiego, Gallego, etc. Sobre la inclusión de autoridades en el DA, véanse Jiménez Ríos (1998), Rusthaller (2000) y la tesis doctoral de Freixas (2003).

21. Para los aspectos de las etimologías en el DA, véanse los trabajos de Alvar Ezquerra (1983) y Jiménez Ríos (2001); este último estudia especialmente los aspectos de la etimología latina en este diccionario.

22. La negrita es nuestra. 
GABACHO. s. m. Soez, asqueroso, sucio, puerco y ruin. Es voz de desprecio con que se moteja à los naturales de los Pueblos que están à las faldas de los Pyrenéos entre el rio llamado Gaba, porque en ciertos tiempos del año vienen al Reino de Aragón, y otras partes, donde se ocupan y exercitan en los ministerios más baxos y humildes. Lat. Bardus, vilis, despicatus homo. QUEV. Mus. 6. Rom. 17.

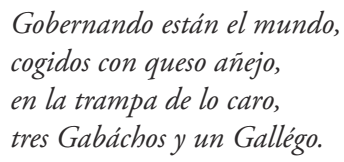

Merecería la pena detenerse en la información enciclopédica que se aporta en algunas de las definiciones. Lógicamente, donde más abunda es en los artículos de las entradas gentilicias que dan cuenta de las lexicalizaciones y por supuesto en las de los seudogentilicios. En general, se formula como información descriptiva, como se ve en la de gabacho. Pero a menudo esa información supuestamente descriptiva es la expresión de una ideología, y la definición de gitANo (y por ende EgIPCIANO, que el DA remite a gitano (Herrera Santana 2016b), que reproducimos es una buena muestra de ello:

GITANO, NA. s. m. yf. Cierta classe de gentes, que afectando ser de Egypto, en ninguna parte tienen domicilio, y andan siempre vagueando. Engañan à los incáutos, diciéndoles la buena ventúra por las rayas de las manos y la phisonomia del rostro, haciendoles creer mil patrañas y embustes. Su trato es vender y trocar borricos y otras béstias, y à vueltas de todo esto hurtar con grande arte y sutileza. Lat. Cingarus. CERV. Nov. 1. pl. 1. Los Gitános y Gitánas parece que solamente nacieron en el mundo para ser ladrones.

GITANO. Por analogía se llama el sugéto advertido, difícil de engañar, y que sabe dirigir y executar con destreza y astúcia sus negócios. Latín. Callidus. Astutus.

GITANO. Se llama tambien el que tiene atractivo en lo que dice y habla, aunque no sea para engañar: y assi se dice es mui gitána, por ser mui halagüeña y cariñosa. Lat. Captator. Allector.

En las definiciones de estos gentilicios se ofrece poca información de las marcas de uso. En algún caso se anotan algunas, sin abreviaturas, como en boemiano, del que se dice que «Es voz antiquada de Aragón, tomada del Francés Boemien», es decir, se indica al mismo tiempo su empleo desusado y su restricción diatópica ${ }^{23}$. O en CIBDADANO, que se remite a CIUDADANO con la sola indicación de «Es voz antiquada». En CORITo tenemos la información completa: anticuado para referirse a los montañeses y vizcaínos y en la actualidad, marcado como «Oy», para aludir a los asturianos en contextos no formales: «por zumba y chanza». Para alguno de ellos se indica expresamente una marca connotativa, como en GABACHO, del que se señala que «Es voz de desprecio». De otras como hispano e ibero se indica su registro: «Es voz Poética» $\mathrm{y}$ «Usase más freqüentemente en la Poesía.», respectivamente.

23. Sobre las localizaciones geográficas en el DA, véanse los trabajos de Alvar Ezquerra (1983) y Le Men Loyer (2001). 
La naturaleza y el tipo de expresiones fraseológicas que se consignan como ejemplos o subentradas gentilicias merecería un estudio detallado que excede los límites de este trabajo. En primer lugar, porque fue voluntad consciente y declarada por la Academia en el título mismo del diccionario ${ }^{24}$ : Diccionario de la lengua castellana, en que se explica el verdadero sentido de las voces, su naturaleza y claridad, con las phrases o modos de hablar, los proverbios o refranes $y$ otras cosas convenientes al uso de la lengua. Y, en segundo lugar, porque ese empeño tuvo resultados diversos. Por un lado, algunas de ellas son más un ejemplo de desarrollo de la acepción personal en acepciones secundarias, terciarias, etc., que una expresión fija propiamente dicha, como se puede ver en la expresión adverbial «En Castellano. adv. Lo mismo que en Lengua Castellana: lo que se entiende de lo que se habla y escribe.» (s. v. CaStellano). Otras sí parecen ser unidades fraseológicas, pues en ellas se ha producido una fijación derivada de la coocurrencia habitual, como en la colocación nominal vela latina que se anota como subentrada de LATINO:

Vela latina. Una vela triangular de que usan las Galeras, Saetías, Bergantínes, Tartanas y otras embarcaciones que navegan en el Mediterráneo, y con menos viento hacen más camino que las velas redondas. Viran sobre el árbol en que suelen peligrar si el viento es grande. Pudo llamarse asi por haberlas inventado y usado los Latinos. Lat. Latinum velum triangulare.

O en la locución verbal estar en arábigo:

Estar en arábigo. Phrase común y familiár, para dár à entender que una cosa está mui obscurra, sumamente dificil de entenderse, y tan revesada è intrincada, que no se percibe lo que se quiere decir, ù dár á entender. Lat. Sermo obscurus, intellectu difficillimus.

Un estudio global de las palabras gentilicias del DA, es decir, de los gentilicios con función gentilicia (objeto de este trabajo) y de las fijaciones léxicas adjetivas y sustantivas que se anotan en su entrada principal o en las subentradas en este repertorio, probablemente arrojaría mucha luz sobre las unidades fraseológicas (más o menos fijadas, más o menos opacas) en las que intervienen estas unidades, y permitiría explicar la lexicalización como el resultado de diversos procesos de especialización sémica y de recategorización a partir de la combinatoria frecuente en que entraban esos gentilicios cuando se referían a lo perteneciente a los naturales de un territorio, es decir, a las acepciones secundarias, terciarias, etc., que se iban generando: de pájaro canario 'pájaro de Canarias' > canario 'pájaro canario' > canario 'cierto tipo de pájaro'.

Como se ha podido ver a través de todo lo expuesto, el DA va más allá del Tesoro de Covarrubias en muchos aspectos. Por un lado, porque, a pesar de registrar un número mucho menor de unidades gentilicias, les otorga valor lexicográfico al concederles entrada independiente para dar cuenta de ellos como palabras adjetivas y no como meros derivados toponímicos. Por otro lado, y aunque como se ha visto hay una falta de regularidad en los

24. La negrita es nuestra. 
criterios adoptados o intuidos, los artículos revelan una voluntad de definir lexicográficamente. Visto hoy en día, resulta muy excesiva la afirmación de don Balthasar de Acevedo, Escribano de Cámara del rey, recogida en las primeras páginas de la obra, quien destacaba en el $\mathrm{DA}$ «[...] la maduréz, diligéncia y reflexión con que está dispuesta y executada: pues además de la igualdád en el méthodo, que con tanto esméro se halla observada en lo crecido del assunto, se registra una exactissima uniformidád en la descripción de las voces [...]». Pero es cierto que, a pesar de la nula preparación filológica que tenían los primeros académicos, «aquellos ocho españoles de Las Descalzas», al decir de Lázaro Carreter (op. cit., 29), fueron capaces de intuir los dos grandes ámbitos en que se usan los gentilicios y trataron de darles formato de definición lexicográfica, separando, en la medida en que les fue posible, las definiciones de los sentidos propiamente gentilicios de los que en aquel momento se habían fijado, las que llamamos lexicalizaciones gentilicias.

En el Tesoro apenas hay gentilicios fuera de las entradas relativas a topónimos, en el Diccionario de Autoridades no hay entradas de topónimos y hacen aparición tímidamente los primeros gentilicios, pero ya en él se sientan las bases de la definición de estas unidades, que entrarán profusamente en la siguiente edición del diccionario académico de 1780, avanzando en lo que a las entradas, las acepciones y su definición se refiere, ya sin autoridades.

\section{Referencias bibliográficas}

Almela Pérez Ramón, «Los sufijos gentilicios: un grupo tan indiscutible como erróneo», Cálamo FASPE, 2013, 61, 12-21.

Alvar Ezquerra Manuel, «Los prólogos del Diccionario académico. Nomenclatura específica y microestructura», Revista de Filología Española, 1983, LXIII, 3-4, juliodiciembre, 205-222.

Alvar Ezquerra Manuel, Tesoro léxico de las hablas andaluzas, Madrid, Arco/Libros, 2000.

Benveniste Émile, «Dos modelos lingüísticos de la ciudad», en Benveniste Émile, Problemas de lingüistica general II, México, Siglo XXI Editores, 1970, 274-282.

Blecua Perdices José Manuel, Principios del Diccionario de Autoridades. Madrid, Real Academia Española, 2006.

Cela Camilo José, Diccionario geográfico popular de España. I. Introducción a la dictadología tópica. España, Madrid, Noesis, 1998.

CLAVE. Maldonado González Concepción (dir.), Diccionario de uso del español actual, Madrid, Ediciones SM, $1997^{2}$.

Covarrubias Horozco Sebastián de, Tesoro de la lengua castellana, o española, edición integral e ilustrada de Ignacio Arellano y Rafael Zafra, Madrid/Frankfurt am Main, Iberoamericana/Vervuert, 2006/1611.

Cruz Herrera María del Pilar, La formación de gentilicios, seudogentilicios y otros dictados tópicos en las comunidades de Madrid y Castilla-La Mancha, Tesis Doctoral defendida en la Universidad Autónoma de Madrid, 1997. 
De la Torre Aparicio Tomás, Diccionario de gentilicios: Toponímicos españoles, Madrid, Vision Net, 2006.

Freixas Alás Margarita, "La técnica lexicográfica en el Diccionario de Autoridades: la contribución del académico Juan Ferreras», en Campos Souto Mar y Pérez Pascual José Ignacio (eds.), El Diccionario de la Real Academia Española: ayer y hoy, A Coruña, Universidade da Coruña, Anexos de Revista de Lexicografía, 1, 2006, 83-97.

Freixas Alás Margarita, «Los modelos lexicográficos del Dicccionario de Autoridades: el Vocabolario degli accademici della Crusca», en Corrales Zumbado Cristóbal et al. (eds.), Nuevas aportaciones a la historiografía lingüistica. Actas del IV Congreso Internacional de la SEHL (Tenerife, Universidad de La Laguna, 22 al 25 de octubre de 2003), I, Madrid: Arco/Libros, 2004, 517-528.

Freixas Alás Margarita, Las autoridades en el primer diccionario de la Real Academia Española, Tesis doctoral defendida en la Universidad Autónoma de Barcelona, 2003. Disponible en http://www.tesisenred.net/handle/10803/4866

Garcés Gómez M. a Pilar, "La formación de gentilicios en varias zonas españolas», en Ariza Manuel, Salvador Antonio y Viudas Antonio (eds.), Actas del I Congreso Internacional de Historia de la Lengua Española, Madrid, Arco Libros, 1988, 16851696.

García Gallarín Consuelo, «Los gentilicios en la historia del español», en Girón Alconchel José Luis et al. (eds.), Estudios ofrecidos al profesor José Jesús de Bustos Tovar, vol. 1, Madrid, Editorial Complutense, 2003, 579-598.

García Padrón Dolores y Morera Marcial, "Gentilicios y lexicografía», Onomázein, 2015, 31,1, 81-98.

García Padrón Dolores, «La derivación no canónica de los gentilicios españoles», en Wotjak Gerd, García Padrón Dolores y Fumero Pérez, María del Carmen (eds.), Estudios sobre lengua, cultura y cognición, Frankfurt am Main, Peter Lang, 2012, 79-87.

García Padrón Dolores, «Procedimientos lingüísticos y socio-pragmáticos en la formación de seudogentilicios: machupichu - machupin, na - machupino, na y guachupino, na», Iberoromania, 2015, 82, 240-256.

Garrido-Moraga Antonio Manuel, «Un episodio en la lexicografía académica de XVIII. Las supresiones en la segunda impresión del diccionario», Rilce, 1992, 8/2, 265-285.

Garrido-Moraga Antonio Manuel, «Un episodio en la lexicografía académica del XVIII. Las incorporaciones en la segunda impresión del diccionario», LEA, 1987, 9/2, 199-206.

Garriga Cecilio, Las marcas de uso en el Diccionario de la Academia: evolución y estado actual, Tesis doctoral defendida en la Universitat Rovira i Virgili, 1993.

Gili Gaya Samuel, La lexicografía académica del siglo XVIII, Oviedo, Universidad de Oviedo, 1963.

Hernando Cuadrado Luis Alberto, «El Diccionario de Autoridades (1726-1739) y su evolución», Verba, 1997, 24, 387-401.

Herrera Santana Juana, «La descripción de la competencia comunicativa en los gentilicios de uso no formal en el DRAE-01», en Nomdedeu Rull Antoni, Forgas 
Berdet Esther y Bargalló Escrivà Maria (eds.), Avances de Lexicografía Hispánica, Tarragona, Servicio de Publicaciones de la Universitat Rovira i Virgili, 2012a, 171178.

Herrera Santana Juana, «Los sufijos y la relación gentilicia en español: su tratamiento lexicográfico», en Cotelo García Rosalía (coord.), Bordeando los márgenes. Gramática, lenguaje técnico y otras cuestiones fronterizas en los estudios lexicográficos, San Millán de la Cogolla, Colección Monografías 16, 2016a, 189-201.

Herrera Santana Juana, «El tratamiento lexicográfico de los gentilicios gitano, judio y moro en los diccionarios académicos», en Domínguez-Rodríguez M. ${ }^{a}$ Victoria et al (eds), Words across History: Advances in Historical Lexicography and Lexicology, Servicio de Publicaciones y Difusión Científica de la Universidad de Las Palmas de Gran Canaria, 2016b, 250-261.

Herrera Santana Juana, «Las marcas sociolingüísticas en los gentilicios y su tratamiento lexicográfico», en Wotjak Gerd, García Padrón Dolores y Fumero Pérez M.a del Carmen (eds.), Estudios sobre lengua, cultura y cognición, Frankfurt am Main, Peter Lang, 2012b, 111-118.

Lázaro Carreter Fernando, Crónica del Diccionario de Autoridades (1713-1740), Madrid, Real Academia Espańola, Biblioteca Nueva, 1972/2014.

Le Men Loyer Janick, «Las localizaciones geográficas en los diccionarios académicos (desde el Diccionario de Autoridades hasta el DRAE-92)», en Maqueira Rodríguez Marina, Martínez Gavilán M. ${ }^{a}$ Dolores y Villayandre Llamazares Milka (eds.), Actas del II Congreso Internacional de la Sociedad Española de Historiografía Lingüistica, Madrid, Arco/Libros, 1999, 623-630.

Morera Marcial y García Padrón Dolores, «Desarrollos semánticos de los gentilicios hispánicos», Zeitschrift für romanische Philologie, 2015, 131 (1), 157-184.

Morera Marcial, "Gentilicios y seudogentilicios: mostración vs. descripción», Revista de Lexicografía, 2012a, XVIII, 103-140.

Morera Marcial, «La ampliación designativa de los gentilicios», en Wotjak Gerd, García Padrón Dolores y Fumero Pérez María del Carmen (eds.), Estudios sobre lengua, cultura y cognición, Frankfurt am Main, Peter Lang, 2012b, 187-194.

Morera Marcial, «La norma morfológica de los gentilicios españoles: del topónimo al gentilicio y del gentilicio al topónimo», en Waluch-de la Torre Edita (ed.), La norma lingüística del español, Varsovia, Instituto de Estudios Ibéricos e Iberoamericanos de la Universidad de Varsovia, 2010, 71-79.

Morera Marcial, «Los adjetivos gentilicios en el Tesoro de la lengua castellana o española, de Sebastián de Covarrubias», en Actas del 7th International Conference on Historical Lexicography and Lexicology, 2015.

Pérez Vigaray Juan M. y Herrera Santana Juana, «El artículo lexicográfico de los sufijos con acepción gentilicia en español: su tratamiento en el DRAE-01» (en prensa).

Real Academia Española, Diccionario de Autoridades. Edición facsímil, 3 vols., Madrid, Gredos, 1726-1739/1990.

Real Academia Española, Diccionario de la lengua española, 22. a ed. Madrid, Espasa, 2001. Disponible en http://lema.rae.es/drae/

Real Academia Española, Diccionario de la lengua española, 23. a ed. Madrid, Espasa, 2014. 
Real Academia Española, Nueva gramática de la lengua española. Morfología. Sintaxis I, Madrid, Asociación de Academias de la Lengua Española, 2009.

Rusthaller Stefan, "Las autoridades en el Diccionario de Autoridades», en Rusthaller Stefan y Prado Aragonés Josefina (eds.), Tendencias en la investigación lexicográfica del español. El diccionario como objeto de estudio lingüistico y didáctico (Actas del Congreso celebrado en la Universidad de Huelva del 25 al 27 de noviembre de 1998), Huelva, Servicio de Publicaciones de la Universidad de Huelva, 2000, 193-224.

Sánchez Salas Gaspar, La formación de gentilicios, seudogentilicios y otros dictados tópicos en la provincia de Jaén, Barcelona, Ediciones Carena, 2009. 
